\title{
Intrahepatic Bile Duct Cancer Pathologic TNM Finding v7
}

National Cancer Institute

\section{Source}

National Cancer Institute. Intrahepatic Bile Duct Cancer Pathologic TNM Finding v7. NCI

Thesaurus. Code C90183.

A pathologic finding about one or more characteristics of intrahepatic bile duct cancer, following the rules of the TNM AJCC v7 classification system. Complete pathologic staging consists of evaluation of the primary tumor, including tumor number, involvement of local regional lymph nodes, and the presence or absence of vascular invasion. (from AJCC 7th Ed.) 